\title{
Impact of a Single Spoiler on Scouring Depth Status Beneath a River Crossing Inclined Pipeline
}

\author{
Saeed Abbasi \\ Department of Civil Engineering \\ University of Zanjan \\ Zanjan, Iran \\ abbasi.saeed@znu.ac.ir
}

\author{
Maryam Masoomi \\ Department of Civil Engineering \\ University of Zanjan \\ Zanjan, Iran \\ m.masoomi@znu.ac.ir
}

\author{
Seyyed Aliasghar Arjmandi \\ Department of Civil Engineering \\ University of Zanjan \\ Zanjan, Iran \\ arjmandi@znu.ac.ir
}

\begin{abstract}
Deep river crossing pipelines utilized to carry fluids are often placed upon the sand bed. Placement of pipe on the non-smooth bed would result in the production of some local gaps beneath the pipe. Asymmetric scouring is one of the main reasons for pipe underwater failures which are significant in pipeline management. So, in designing pipelines, knowing the interaction between pipelines and bed, and predicting the scour depth with respect to the pipe distance from the bed is significant to ensure that the pipe will finally deposit on the bed. Numerical models have been developed for predicting the balance depth of scouring beneath the pipelines. In this paper, the impact of pipe orientation on maximum scour depth beneath the pipelines is investigated. To do this, a pipe is modeled with various angles with the flow. To manage the local scouring, some spoilers are placed and modeled upon some pipes too. Also, in order to know the effects of placement of a pipe at various distances from the bed, the impact of placement of each pipe at a distance of $0.2 \mathrm{D}$, 0.4D and 0.6D is investigated as well. To model the pipe with and without a spoiler, the finite element model Flow-3D is utilized and the results show good accordance with previous experimental studies and proof the current model's precision in predicting the scour depth. Results show that in the placement of the pipe in angles not investigated before and also with the installing of a spoiler, the scour process has a reverse ratio with the distance which would result in full deposition of the pipe on the bed. The least scour depth belongs to the condition in which the pipe has a $130^{\circ}$ angle with the side wall.
\end{abstract}

Keywords-Flow-3D; pipeline; pipe orientation; pipe with spoiler; scouring

\section{INTRODUCTION}

Submerged pipes are significant parts of water conveying systems, wastewater networks, and oil transmitting lines. Sediment movement under the pipes is very important because failure of these pipes would cause huge costs and damages on the environment. The local scouring at the river is investigated in [1]. During the water transmission around a pipe situated at the flow path, collide of the streamlines to an obstacle would produce several vortices around the pipe. The vortices move the sediment particles until a small void is produced beneath the pipe which causes tunnel erosion [2]. Scouring of the soil under the pipe might suspend a part of the pipe in the water and if the free span of the pipe is big enough, it would result to vibration resonance and might lead to pipe failure. So it is essential to assess the scouring depth to be able to make an exact and secure design. Preparing a spoiler on the pipe is a method to accelerate the pipe self-interring (Figure 1).

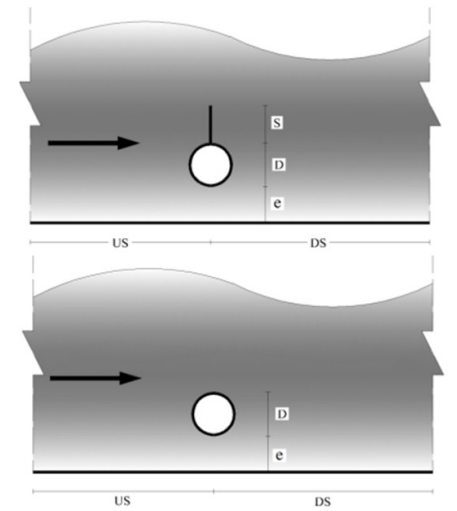

Fig. 1. Pipe on the flow path: up: with spoiler, down: without spoiler

Several researches have been performed on scouring phenomena around a pipeline. In these studies, the pipe is placed perpendicular to the flow path, while it is not always possible to install the pipe perpendicular to the flow path. Authors in [3] showed that for the pipe with a spoiler the selfinterring process is ten times faster than that for a pipe with no spoiler. Author in [4] investigated the scouring around a horizontal cylinder under various Reynolds numbers (Re), various Shields parameters $(\theta)$ and various distances from the bed and introduced two small vortices on pipe upstream and downstream. Author in [5] showed that the scour depth could be considered as a function of Froude number and the free distance between the pipe and the bed. Author in [6, 7], experimentally investigated the impact of spoiler and its orientation on a pipe subjected to wave and a one-way flow. He showed that the installation of spoiler would accelerate the under pipe scouring (tunnel erosion) and also increase the erosion on downstream and its depth. Authors in [8] investigated the scouring under the pipe experimentally and studied the impact of Froude and Reynolds numbers on it. Author in [9] studied the flow and scouring beneath the pipe 
utilizing K- $\varepsilon$ turbulence model using Taylor-Galerkin FEM method. Authors in [10] showed that a standing spoiler considerably increases the upstream pressure, reduces the downstream pressure and causes a downward force. Authors in $[11,12]$ showed that the $\mathrm{K}-\omega$ turbulence model is more adaptive than K- $\varepsilon$ and a special case of LES turbulence models. Authors in [13] investigated numerically the scouring beneath the pipe under one-way flow and wave. Authors in $[14,15]$ investigated numerically the scouring under the pipe with spoiler and its impact on flow characteristics. Authors in [16] studied the hydrodynamic effects of a horizontal spoiler on the flow around a pipe and concluded that the length of 1-1.5 times the pipe diameter for the spoiler is optimum. Authors in [1] investigated a river crossing inclined pipeline experimentally and authors in [17] modeled the flow around a cylinder over a scoured bed. Despite that experimental models are accurate and suitable for scour depth estimation, some limitations such as costs, scaling, data acquiring and also some benefits of the numerical methods such as flexibility and considerable improvement of their potentials, have expanded the use of numerical simulations. In this paper, the impact of spoiler installation on an inclined river crossing pipeline on local scour depth is numerically investigated. Also, in addition to the spoiler presence, effects of bed-pipeline distance are included in this paper which was not studied in [1].

\section{GOVERNING EQUATIONS}

The governing equations are continuity and momentum equations. To include the sediment effects, some changes are applied to these equations. The continuity and momentum equations are presented in (1)-(5):

$$
\begin{aligned}
& V_{F} \frac{\partial \rho}{\partial t}+\frac{\partial}{\partial x}\left(\rho u A_{x}\right)+R \frac{\partial}{\partial y}\left(\rho u A_{y}\right)+\frac{\partial}{\partial z}\left(\rho u A_{z}\right)+\xi \frac{\rho u A_{x}}{x}=R_{D I F}+R_{S O R} \\
& \frac{V_{F}}{\rho c^{2}} \frac{\partial \rho}{\partial t}+\frac{\partial u A_{x}}{\partial x}+R \frac{\partial v A_{y}}{\partial y}+\frac{\partial w A_{z}}{\partial z}+\xi \frac{u A_{x}}{x}=\frac{R_{S O R}}{\rho} \\
& \frac{\partial u}{\partial t}+\frac{1}{V_{F}}\left(u A_{x} \frac{\partial u}{\partial x}+v A_{y} R \frac{\partial u}{\partial y}+w A_{z} \frac{\partial u}{\partial z}\right)-\xi \frac{A_{y} v^{2}}{x V_{F}} \\
& =-\frac{1}{\rho} \frac{\partial p}{\partial x}+\cdots+G_{x}+f_{x}-b_{x}-\frac{R_{S O R}}{\rho V_{F}}\left(u-u_{w}-\delta u_{s}\right) \\
& \frac{\partial u}{\partial t}+\frac{1}{V_{F}}\left(u A_{x} \frac{\partial v}{\partial x}+v A_{y} R \frac{\partial v}{\partial y}+w A_{z} \frac{\partial v}{\partial z}\right)-\xi \frac{A_{y} u v}{x V_{F}} \\
& =-\frac{1}{\rho}\left(R \frac{\partial p}{\partial y}\right)+\cdots+G_{y}+f_{y}-b_{y}-\frac{R_{S O R}}{\rho V_{F}}\left(u-u_{w}-\delta u_{s}\right) \\
& \frac{\partial u}{\partial t}+\frac{1}{V_{F}}\left(u A_{x} \frac{\partial w}{\partial x}+v A_{y} R \frac{\partial w}{\partial y}+w A_{z} \frac{\partial w}{\partial z}\right) \\
& =-\frac{1}{\rho} \frac{\partial p}{\partial z}+G_{z}+\cdots+f_{z}-b_{z}-\frac{R_{S O R}}{\rho V_{F}}\left(u-u_{w}-\delta u_{s}\right) \\
& V_{F} \frac{\partial F}{\partial t}+\nabla \cdot(A U F)=0
\end{aligned}
$$

where $V_{F}$ is the proportion of open volume to the flow, $\rho$ is the fluid density and $R_{S O R}$ is the spring function. The fluid particle movement equations in three directions are Navier-Stocks equations with an additional term. Also, $A_{x}, A_{y}$, and $A_{z}$ are volume ratios, $G_{x}, G_{y}$ and $G_{z}$ are gravitational accelerations, $f_{x}$, $f_{y}$ and $f_{z}$ are viscosity accelerations and $b_{x}, b_{y}$ and $b_{z}$ are dissipations in porous media in $x, y$ and $z$ directions respectively. Equation (6) is the VOF equation in which $A$ is mean flow cross-sectional area, $U$ is mean flow velocity in $x, y$ and $z$ directions and $F$ is fluid volume function. In Flow-3D, two methods, VOF (to model the performance of the fluid at the open boundary with air) and FAVOR (to model the rigid volumes and surfaces such as geometric boundaries) are used to model the interactions [18].

\section{A. The K- $\omega$ Model}

The $\mathrm{K}-\omega$ turbulence model is a two-equation model which uses two partial differential equations with two variables of $K$ and $\omega$. The first variable $(K)$ is turbulent kinetic energy and the second one $(\omega)$ is dispersion characteristic velocity $[19,20]$. The related equations of this model are presented in (7-9).

$$
\begin{aligned}
& v_{t}=\frac{k}{\omega} \\
& \frac{\partial k}{\partial t}+U_{j} \frac{\partial k}{\partial x_{j}}=\tau_{i j} \frac{\partial U_{i}}{\partial x_{j}}-\beta^{*} k \omega+\frac{\partial}{\partial x_{j}}\left[\left(v+\sigma^{*} v_{T}\right) \frac{\partial k}{\partial x_{j}}\right] \\
& \frac{\partial \omega}{\partial t}+U_{j} \frac{\partial \omega}{\partial x_{j}}=\alpha \frac{\omega}{k} \tau_{i j} \frac{\partial U_{i}}{\partial x_{j}}-\beta \omega^{2}+\frac{\partial}{\partial x_{j}}\left[\left(v+\sigma v_{T}\right) \frac{\partial \omega}{\partial x_{j}}\right]
\end{aligned}
$$

where $\alpha=\frac{5}{9}, \beta=\frac{3}{40}, \beta^{*}=\frac{9}{100}, \sigma=\frac{1}{2}, \sigma^{*}=\frac{1}{2}, \varepsilon=\beta^{*} \omega k$

\section{B. Dimensional Analysis}

The effective parameters in local scouring beneath the pipeline in a channel are flow conditions, sediments characteristics and pipe shape $[1,8]$. The relation between the mentioned parameters can be written as:

$$
d_{s}=f\left(\rho, \rho_{s}, v, y, g, d_{50}, S_{f}, D, e, s\right)
$$

where $d_{s}$ is scouring balance depth, $\rho$ is flow density, $\rho_{s}$ is sediment density, $v$ is kinematic viscosity, $y$ is flow depth, $g$ is gravitational acceleration, $d_{50}$ is mean particle size, $S_{f}$ is energy line slope, $D$ is pipe diameter, $e$ is bed-pipe distance and $s$ is the spoiler length. Utilizing the Buckingham's $\Pi$ theorem and neglecting the Reynolds number effects, we get:

$$
\frac{d_{s}}{y}=\psi\left(\frac{d_{50}}{y}, \frac{D}{y}, \frac{e}{y}, \frac{s}{y}, F r, \tau^{*}, \theta\right)
$$

in which $F r$ is Froude number, $\tau^{*}$ is Shields parameter and $\theta$ is the angle of pipe orientation.

\section{THE NUMERICAL SOLUTION, ANALYTICAL DOMAIN}

In this paper, the experimental work of [21] for a fixed pipe is used to validate the model. In the experimental work, the width of the flume is $0.5 \mathrm{~m}$, the pipe diameter is $0.032 \mathrm{~m}$, the flow velocity is $0.255 \mathrm{~m} / \mathrm{s}$, sediment particle mean size is $0.38 \mathrm{~mm}$ and the Shields parameter is evaluated as 0.039 . In the numerical model, the $\mathrm{K}-\omega$ turbulence model is used; the pipe is placed at a distance of $10 \mathrm{D}$ from the beginning and at various distances from the bed. The depth of flow is $0.40 \mathrm{~m}$ and two nested mesh of $10 \mathrm{~mm}$ and $5 \mathrm{~mm}$ are utilized for the outer and 
inner domain (around the pipe) respectively. Figure 2 shows the analytical domain.

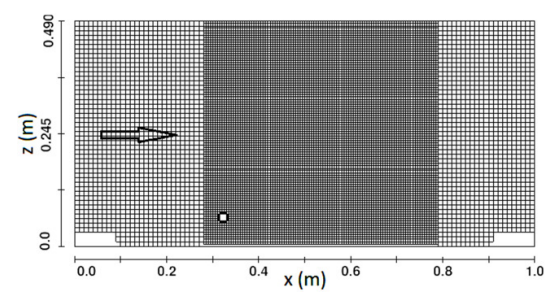

Fig. 2. Analytical domain

With respect to the orientation angle, the pipe and flow can be at three situations: 1) perpendicular to the river, 2) parallel to the flow, and 3) inclined crossing [22]. In this paper, an inclined pipe with angles of $90^{\circ}, 100^{\circ}, 110^{\circ}, 120^{\circ}$ and $130^{\circ}$ at various bed-pipe distances is investigated. Figure 3 shows the inclined pipe and Table I represents the numerical model's layout.

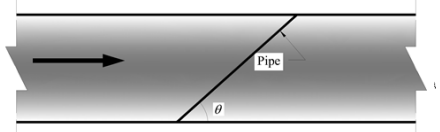

Fig. 3. Inclined pipe on the flow path

TABLE I. NUMERICAL MODELS LAYOUT

\begin{tabular}{|c|c|c|c|c|}
\hline \multicolumn{2}{|c|}{ Pipe angle $\boldsymbol{\theta}$ (Deg.) } & \multicolumn{3}{c|}{ Bed-Pipe distance } \\
\cline { 2 - 5 } & $90^{\circ}$ & 0.2D & 0.4D & 0.6D \\
\hline \multirow{4}{*}{ Pipe without spoiler } & $100^{\circ}$ & $\mathrm{A} 2$ & $\mathrm{~B} 2$ & $\mathrm{C} 1$ \\
\cline { 2 - 5 } & $110^{\circ}$ & $\mathrm{A} 3$ & $\mathrm{~B} 3$ & $\mathrm{C} 3$ \\
\hline & $120^{\circ}$ & $\mathrm{A} 4$ & $\mathrm{~B} 4$ & $\mathrm{C} 4$ \\
\hline & $130^{\circ}$ & $\mathrm{A} 5$ & $\mathrm{~B} 5$ & $\mathrm{C} 5$ \\
\hline \multirow{4}{*}{ Pipe with spoiler } & $90^{\circ}$ & $\mathrm{A} 6$ & $\mathrm{~B} 6$ & $\mathrm{C} 6$ \\
\hline & $100^{\circ}$ & $\mathrm{A} 7$ & $\mathrm{~B} 7$ & $\mathrm{C} 7$ \\
\cline { 2 - 5 } & $110^{\circ}$ & $\mathrm{A} 8$ & $\mathrm{~B} 8$ & $\mathrm{C} 8$ \\
\cline { 2 - 5 } & $120^{\circ}$ & $\mathrm{A} 9$ & $\mathrm{~B} 9$ & $\mathrm{C} 9$ \\
\cline { 2 - 5 } & $130^{\circ}$ & $\mathrm{A} 10$ & $\mathrm{~B} 10$ & $\mathrm{C} 10$ \\
\hline
\end{tabular}

\section{A. Boundary Conditions}

Nested mesh was used to model the flow in this study. To apply the boundary conditions, the specified velocity was applied to the inlet boundary. The Outflow is used for the outlet boundary and the Symmetry is applied to the upper boundary. For the other borders, the Wall boundary condition was utilized. These boundary conditions are shown in Figure 4.

\section{B. Validation}

The results of an experimental work in [21] show that the balance depth of scouring beneath a pipe was $1.34 \mathrm{~cm}$. The result of numerical simulation was $1.39 \mathrm{~cm}$ which shows a good accordance with the experimental work. The relative error is $3.73 \%$ which shows a good precision of numerical simulation under a submerged pipe. Comparison of numerical and experimental work and balance reaching process for the numerical model are shown in Table II and Figure 5 respectively.

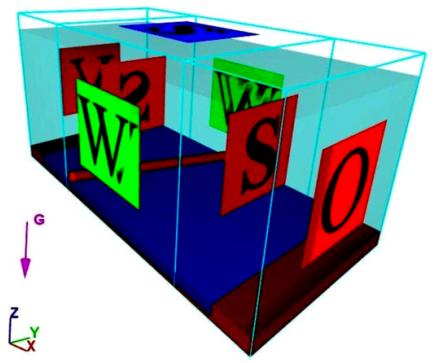

Fig. 4. The boundary conditions

TABLE II. NUMERICAL AND EXPERIMENTAL RESULT COMPARISON

\begin{tabular}{|c|c|c|}
\hline & Scouring depth (cm) & Error \% \\
\cline { 1 - 2 } Experimental [21] & 1.34 & \multirow{2}{*}{$3.73 \%$} \\
\hline Numerical (Flow-3D) & 1.39 & \\
\hline
\end{tabular}

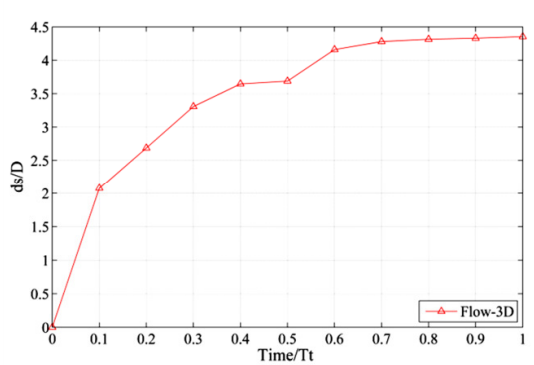

Fig. 5. Balance reaching process for the scouring under the pipe, numerical model validation

\section{RESULTS AND DISCUSSION}

\section{A. Results for Pipe Placement without Spoiler at Various Bed-Pipe Distances}

To investigate the impact of pipe inclined placement on the flow path, the following characteristics were applied to the numerical model: Pipe diameter $=0.032 \mathrm{~m}$, water velocity $=0.255 \mathrm{~m} / \mathrm{s}$, sediment particle mean size $d 50=0.38 \mathrm{~mm}$, channel width $=0.5 \mathrm{~m}$ and Shields parameter $=0.039$. The pipe was oriented at $90^{\circ}, 100^{\circ}, 110^{\circ}, 120^{\circ}$ and $130^{\circ}$ measured from the side wall (Figure 3). To investigate the bed-pipe distance effects, the pipe was placed at distances of $0.2 \mathrm{D}, 0.4 \mathrm{D}$ and $0.6 \mathrm{D}$ of the bed.

TABLE III. MAXIMUM DEPTH OF SCOURING BENEATH THE PIPE W/O SPOILER

\begin{tabular}{|c|c|c|c|}
\hline \multirow{2}{*}{ Pipe Angle } & \multicolumn{3}{|c|}{ Bed-pipe distance (cm) } \\
\cline { 2 - 4 } & Ys=0.2D & Ys=0.4D & Ys=0.6D \\
\hline $\mathbf{9 0}^{\circ}$ & 1.39 & 1.29 & 0.88 \\
\hline $\mathbf{1 0 0}^{\circ}$ & 1.40 & 1.34 & 1.06 \\
\hline $\mathbf{1 1 0}^{\circ}$ & 1.41 & 1.34 & 1.03 \\
\hline $\mathbf{1 2 0}^{\circ}$ & 1.34 & 1.29 & 0.84 \\
\hline $\mathbf{1 3 0}^{\circ}$ & 1.15 & 1.02 & 0.75 \\
\hline
\end{tabular}

Figures 7-9 show the simulation results for various distances and orientations. The asymmetric scouring under the pipe in Figure 6 is caused by flow turn, affecting the flow by the walls, vortex pattern change and their expansion path deviation. This asymmetry scouring decreases by increasing the bed-pipe distance because of bed-pipe interaction reduction. 


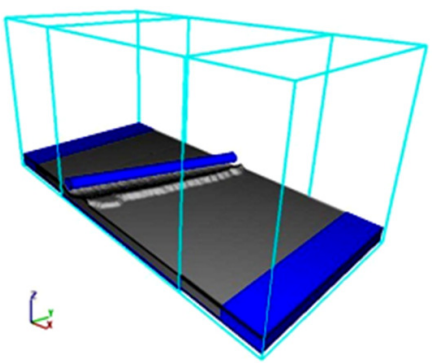

Fig. 6. Numerical simulation sample result, scouring hole beneath inclined pipe, $\theta=130^{\circ}$

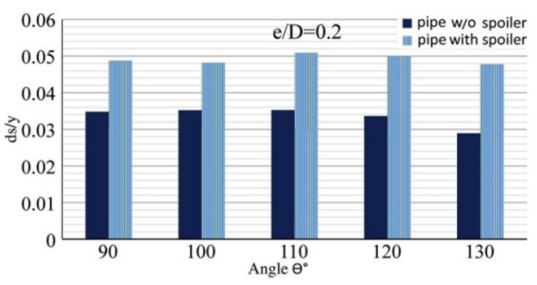

Fig. 7. Scouring beneath the inclined pipe, $e / D=0.2$

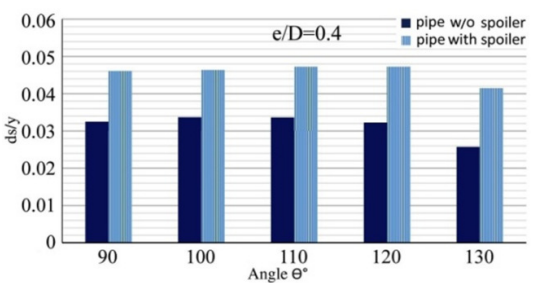

Fig. 8. Scouring beneath the inclined pipe, $e / D=0.4$

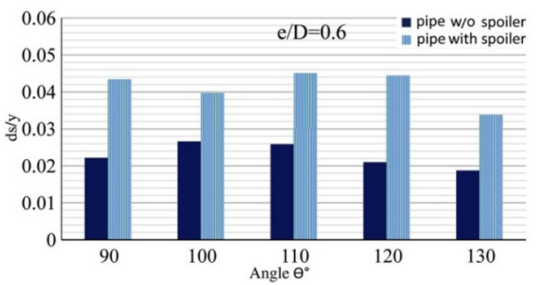

Fig. 9. Scouring beneath the inclined pipe, $e / D=0.6$

\section{B. With Spoiler}

To investigate the impact of spoiler installation around the pipe [23], an $1 \mathrm{~cm}$ length spoiler was installed on top of the pipe and the pipe and spoiler were subjected to the flow. The scouring results of this configuration on orientations of $90^{\circ}$, $100^{\circ}, 110^{\circ}, 120^{\circ}$ and $130^{\circ}$ are presented in Figures 7-9 and Table IV. These results show that installation of the spoilers has increased the depth of scouring compared to a similar situation without spoiler. The spoiler changes the flow and pressure distribution around the pipe and increases the pressure at the rear [10]. Also, results indicate that the scouring depth decreases as the bed-pipe distances increase. Figure 10 shows the scouring progress for the submerged pipe with and without spoiler for $e / D=0.2$. It is evident that the scouring progress in case of utilizing a spoiler is more consistent and continuous which helps the pipe in the self-interring process.
TABLE IV. MAXIMUM SCOURING DEPTH WITH SPOILER

\begin{tabular}{|c|c|c|c|}
\hline \multirow{2}{*}{ Pipe Angle } & \multicolumn{3}{|c|}{ Bed-pipe distance (cm) } \\
\cline { 2 - 4 } & Ys=0.2D & Ys=0.4D & Ys=0.6D \\
\hline $\mathbf{9 0}^{\circ}$ & 1.95 & 1.84 & 1.73 \\
\hline $\mathbf{1 0 0}^{\circ}$ & 1.92 & 1.85 & 1.60 \\
\hline $\mathbf{1 1 0}^{\circ}$ & 2.03 & 1.89 & 1.80 \\
\hline $\mathbf{1 2 0}^{\circ}$ & 2.00 & 1.89 & 1.77 \\
\hline $\mathbf{1 3 0}^{\circ}$ & 1.91 & 1.66 & 1.35 \\
\hline
\end{tabular}
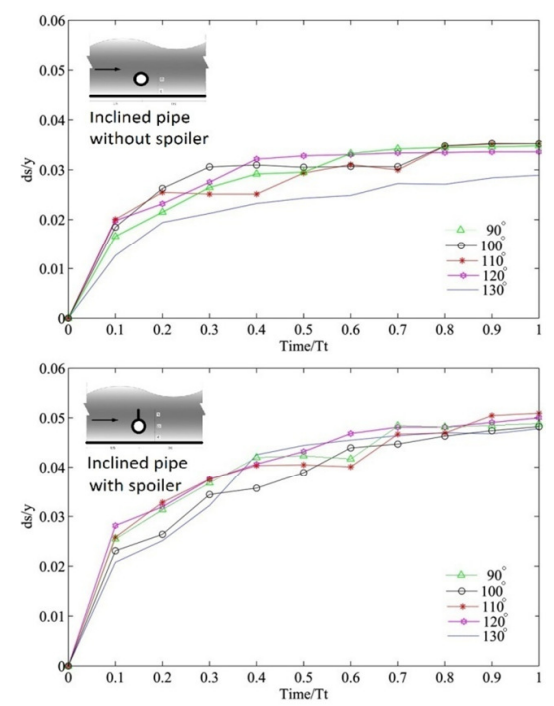

Fig. 10. Scouring progress beneath the inclined pipes, $e / D=0.2$

\section{SUMMARY AND CONCLUSIONS}

In this paper, the effectiveness of a single spoiler on scouring depth reduction beneath a river crossing inclined pipeline at various bed-pipe distances was investigated numerically. Main conclusions are:

- As the scouring depth at the validation model has a balance time of $140 \mathrm{~s}$, the simulation time was selected to be $350 \mathrm{~s}$ for all models.

- Considering the results, the least scouring belongs to the pipe in $130^{\circ}$ orientation and the depth of scouring in orientations of $90^{\circ}, 100^{\circ}, 110^{\circ}$ and $120^{\circ}$ is more by $2.09 \%$, $0.52 \%, 6.28 \%$ and $7 \%$ respectively. The scouring hole is symmetric when the pipes angle is $90^{\circ}$ while the scouring hole for the pipe at $100^{\circ}, 110^{\circ}, 120^{\circ}$ and $130^{\circ}$ is asymmetric. According to the results, the maximum depth of scouring occurs next to the wall in which the pipe angle deflects the flow and the pressure varies upstream and downstream. Sediment transport to the pipes downstream is because of the uplift pressure beneath the pipe and also the pipe orientation. The scouring starts somewhere upstream and slightly travels towards the pipe.

- Maximum scouring depth occurs at the first stages of scouring process. Also, when the bed-pipe distance is more than zero, the scouring starts immediately after the simulation starts, because no time is needed for the piping phenomenon. So the sediment particles under the pipe start their travel immediately after the flow beginning. For angles of $120^{\circ}$ and $130^{\circ}$, the scouring depth balance occurs 
more rapidly and the variation chart extends with fewer slopes. Also, the scouring depth is less than in other orientations. This is because of less resistance of pipe against the flow.

- Placement of the pipe at distances of 0.2D, 0.4D and 0.6D from the bed increases the horizontal distance of deepest scouring hole location from the pipe center. According to Tables III and IV, the bed-pipe distance at five distinct states of orientations has a similar impact on all pipes which proofs the reverse relation of bed-pipe distance with scouring depth. It is seen that the scouring depth decreases with increase in the bed-pipe distance which happens because of the pipe influence reduction on the bed at greater bed-pipe distances.

- Spoiler installation increases the scour depth and extension. The flow rate increases between the pipe and river bed which results to increasing scour depth under the pipe with a spoiler.

- The influence of pipe on the bed scouring depth reduces with an increment of bed-pipe distance at the case of pipe with spoiler and the maximum scouring depths reduce.

\section{REFERENCES}

[1] H. M. Azamathulla, M. A. M. Yusoff, Z. A Hasan, "Scour below submerged skewed pipeline", Journal of Hydrology, Vol. 509, pp. 615620,2014

[2] E. W. Bijker, W. Leeuwestein, "Interaction between pipelines and the seabed under influence of waves and currents", in: Seabed Mechanics, Springer, Dordrecht, 1984

[3] C. H. Hulsbergen, R. Bijker, "Effect of spoilers on submarine pipeline stability", Offshore Technology Conference, Houston, USA, May 1-4, 1989

[4] Y. Mao, The Interaction between a Pipeline and an Erodible Bed, PhD Thesis, Technical University of Denmark, 1986

[5] J. A. Maza, Introduction to river engineering, Advanced Course on Water Resources Management, Universita Italiana per Stranieri, 1987

[6] Y. M. Chiew, "Effect of spoilers on scour at submarine pipelines", Journal of Hydraulic Engineering, Vol. 118, No. 9, pp. 1311-1317, 1992

[7] Y. M. Chiew, "Effect of spoilers on wave-induced scour at submarine pipelines", Journal of Waterway, Port, Coastal, and Ocean Engineering, Vol. 119, No. 4, pp. 417-428, 1993

[8] A. T. Moncada-M., J. Aguirre-Pe, "Scour below pipeline in river crossings", Journal of Hydraulic Engineering, Vol. 125, No. 9, pp. 953958, 1999

[9] B. Brors, "Numerical modeling of flow and scour at pipelines", Journal of Hydraulic Engineering, Vol. 125, No. 5, pp. 511-523, 1999

[10] L. Cheng, L. W. Chew, "Modeling of flow around a near-bed pipeline with a spoiler", Ocean Engineering, Vol. 30, pp. 1595-1611, 2003

[11] D. Liang, L Cheng, F. Li, "Numerical modeling of flow and scour below a pipeline in currents: Part II. Scour simulation", Coastal Engineering, Vol. 52, pp. 43-62, 2005

[12] D. F. Liang, L. Cheng, "Numerical modeling of flow and scour below a pipeline in currents: Part I, Flow simulation”, Coastal Engineering, Vol. 52, pp.25-42, 2005

[13] Y. Zhang, M. Zhao, K. C. S. Kwok, M. M. Liu, "Computational fluid dynamics-discrete element method analysis of the onset of scour around subsea pipelines", Applied Mathematical Modelling, Vol. 39, pp. 76117619,2015

[14] J. P. Zhao, X. C. Wang, "CFD numerical simulation of the submarine pipeline with spoiler", Journal of Offshore Mechanics and Arctic Engineering, Vol. 131, pp. 03601.1-03601.5, 2009
[15] H. Zhu, X. Qi, P. Lin, Y. Yang, "Numerical simulation of flow around a submarine pipe with a spoiler and current-induced scour beneath the pipe", Applied Ocean Research, Vol.41, pp. 87-100, 2013

[16] L. Long, D. Dongshan, M. Xiao, "Research on inhibition effect of vortex-induced vibration of submarine pipeline with horizontal spoilers", The Open Petroleum Engineering Journal, Vol. 7, pp. 92-98, 2014

[17] H. Smith, D. Foster, "Modeling of flow around a cylinder over a scoured bed", Journal of Waterway, Port, Coastal, and Ocean Engineering, Vol. 131, No. 1, pp. 14-24, 2005

[18] Flow Science, FLOW-3D User Manual 11.0.3, Flow Science, 2014

[19] D. C. Wilcox, "Reassessment of the scale-determinant equation for advanced turbulence models", AIAA Journal, Vol. 26, pp. 1299-1310, 1988

[20] D. C. Wilcox, "Formulation of the $k-\omega$ turbulence model revisited", AIAA Journal, Vol. 46, pp. 2823-2838, 2008

[21] F. P. Gao, B. Yang, Y. X. Wu, S. M. Yan, "Steady current induced seabed scour around a vibrating pipeline", Applied Ocean Research Vol. 28, No. 5, pp. 291-298, 2006

[22] Q. Deng, L. Li, Y. Zhang, “An analysis of river washout influence and protective measures of long-distance gas and oil pipelines", International Conference on Pipelines and Trenchless Technology, Wuhan, China, October 19-22, 2012

[23] X. Ruan, B. Shi, L. Yang, Z. Zhang, "An experimental study on scour around the submarine pipeline with spoilers under wave conditions", IEEE 2011 International Conference on Remote Sensing, Environment and Transportation Engineering, Nanjing, China, June 24-26, 2011 